\title{
PREMISSAS DA PREPARAÇÃO DE ADMINISTRADORES
}

FRANCISCO GOMES DE MATTOS

"A preparação de administradores tem, bàsicamente, um sentido preventivo de contrôle de atitudes." NORMAN R. F. MAIER

As responsabilidades da' emprêsa ganham dimensões inteiramente novas no mundo atual. Cada dia novas solicitações, modificações, compromissos... novos desafios exigem dos administradores versatilidade e atualização para poderem - sensíveis às influências de uma sociedade em mudança rápida e, muitas vêzes, radical - ajustar a emprêsa aos novos tempos.

Conhecimentos que ontem eram do domínio de poucos hoje são exigidos às chefias mais simples. Do administrador de hoje e do de amanhã exige-se, cada vez mais, visão global da emprêsa e de tôda a conjuntura econômico-social do meio em que atua. Não basta ao administrador conhecer o seu negócio: êle precisa ter uma visão integrada de todos os elementos que influam e possam vir a influir, a fim de estar preparado quando surgirem inovações que tornem caducos os seus planos e obsoleta a sua atuação. Planejamento, objetivos bem fixados, informação, previsão, atualização de métodos e processos garantem ao administrador a estabilidade que necessita para a tomada de decisões.

Francisco Gomes De Matros - Diretor-Fundador da Escola de Administração Comercial do SENAC $€$ Assessor de Desenvolvimento do Persoal do Banco do Estado da Guanabara S. A.. 
As preocupações de ordem financeira ou de ordem técnica com dinheiro, máquinas, métodos e processos, que caraterizavam as preocupações do dirigente de ontem, não constituem para o dirigente de hoje o centro principal de interêsse. Se a emprêsa cresce, gerando novas responsabilidades, cargos, oportunidades e o compromisso gigantesco de continuar crescendo, que é que vai poder concorrer para êsse progresso ou dificultá-lo? Máquinas? Sistemas? Mercados? Muito mais do que isso: os homens! Daí a necessidade de dirigentes capazes, que saibam decidir sôbre máquinas, sistemas, mercados e todo o complexo de situações que o futuro reserva.

Sôbre os administradores modernos pesa o compromisso de se prepararem para assumir as responsabilidades futuras da emprêsa em crescimento. Hoje, que o segrêdo não é mais a "alma do negócio", pois a técnica e a maquinaria estão à disposição de quem possa comprá-las, uma emprêsa se diferencia das demais e obtém sucesso pela qualidade de seus administradores.

Quem faz a emprêsa são os homens; se êstes não se desenvolvem, a emprêsa não pode crescer autênticamente. Dá pulos para o alto sem pontos de sustentação. Portanto, deve a emprêsa não apenas cuidar do desenvolvimento dos atuais dirigentes, mas do preparo daqueles de que venha a necessitar a curto ou a longo prazo. Só assim poderá garantir sua própria sobrevivência.

Temos assistido a várias organizações tradicionais fecharem as portas por não as terem aberto às possibilidades do futuro. Faltaram-lhes administradores, pois os que possuíam estavam irremediàvelmente comprometidos com o "passado de glórias".

Peter Drucker lembra que a solução para o problema da obtenção de bons administradores não está na orientação que alguns tomam de procurar "homens de apoio", pessoas capazes de tomar o lugar dos executivos de hoje: "É preciso criar administradores capazes de enfrentar as tarefas de amanhã, não as tarefas de ontem”. 
Mas, como preparar administradores? Qual a perspectiva sôbre a qual deva fundamentar-se um programa de formação integral de homens que saibam decidir?

\section{ADMINISTRADOR - AQUÊLE QUE DECIDE}

Para responder a essas questões seguem-se, em geral, como orientação básica, a análise dos dirigentes pela determinação do que êstes fazem na prática, e a análise do cargoo mediante definição das suas caraterísticas essenciais e dos requisitos para seu preenchimento, com especial atenção aos fatôres de personalidade que devam ser mais acentuados.

- O primeiro critério - a análise dos dirigentes pelo que êstes fazem - tem sido adotado largamente como base de programas de treinamento administrativo. Seu uso puro e simples padece de uma deficiência vital: restringe o "ótimo" ao padrão vigente.

Ora, como vivemos numa civilização em mudança vertiginosa, a todo o momento surgem problemas que fazem gorar planejamentos e desafiam a funcionalidade dos sistemas mais avançados de organização.

Não podemos, pois, treinar dirigentes com base apenas no padrão atual, isto é, baseados sòmente nas qualidades $\mathrm{e}$ qualificações dos dirigentes atuais, em suas rotinas e em seu comportamento. Convém que procuremos enxergar além da fronteira do cotidiano.

Não obstante, a análise dos dirigentes é importante como referência, desde que combinada com a análise do cargo.

- O que marca fundamentalmente o cargo de direção é o compromisso de tomar decisões diante de incertezas, de imprevistos, de fatos e problemas não programados. Ao administrador raramente se apresentam situações permanentemente estáveis, esquemas comuns, problemas para aferição de fórmulas consagradas, programações inflexíveis e decisões tranqüilas. $\hat{E}$ na resolução de questões imponderáveis que o administrador enfrenta as alternativas de 
risco, aí capitalizando todo o seu acervo de conhecimentos e experiências. $\mathbf{E}$ é ao decidir sôbre essas questões que êle se revela um bom ou mau administrador, porquanto de sua ação depende, muitas vêzes, o próprio futuro da emprêsa. De bons executivos esperam-se não apenas boas execuções, mas criatividade, iniciativa, espírito renovador.

Assim, a "orientação prática" pretensamente conferida a alguns cursos de treinamento que procuram ensinar a resolver problemas-padrões incorre, a nosso ver, nos seguintes inconvenientes: (a) parte de uma premissa convencionada, (b) estabelece um estado de coisas que passa a ser tido como o "ótimo" a atingir e (c) padroniza a solução e, dêsse modo, bitola o conhecimento.

A orientação aconselhável, a nosso ver, seria a que se empenhasse em incentivar a procura de soluções, sem apresentar a realidade como se ela fôsse estática, bastando partir o bôlo e servir as fatias.

No treinamento administrativo a realidade é considerada, tanto quanto possível, tal como ela é, um desafio que se renova constantemente, exigindo do administrador percepção rápida (para atacar o problema na hora) e ação imediata que abrange: (a) pesquisa de informações (em tôdas as áreas importantes), $(b)$ análise das informações, (c) levantamento das alternativas, (d) escolha da solução, (e) decisão, (f) ação e (g) coordenação e contrôle.

Em administração de emprêsas não existe pròpriamente uma solução para cada problema; existe a solução que o administrador tenha encontrado e pela qual responde. Não se aceita um padrão como verdade cega; é preciso comprová-lo, porque decisão é uma responsabilidade individual.

Para decidir não basta ser um bom especialista e saber liderar a equipe; é preciso possuir visão global, a fim de considerar todos os fatôres de influência. É preciso saber raciocinar em função da multiplicidade de fatôres que interferem no problema. Freqüentemente, por falta de visão integral "resolvem-se" problemas acessórios criando-se problemas capitais. 
Estudos realizados demonstram que o desenvolvimento de um executivo depende, em sua maior parte, da experiência adquirida no trabalho. O exercício bem orientado das funções é o melhor processo de desenvolvimento funcional de seu exeqüente. As iniciativas de formação devem, assim, estar articuladas com o desenvolvimento da função. Um curso de treinamento sem a consideração do desempenho funcional é falho. Por outro lado, o exercício da direção sem adequado preparo e desenvolvimento é ineficiente.

Um programa de desenvolvimento de administradores deve combinar conhecimentos e experiências. $O$ conhecimento não substitui a experiência, nem esta subsiste sem êle. A solução de problemas em aula é útil, mas não basta: falta-lhe a necessária tensão que a realidade provoca no dirigente diante de problemas a resolver. Combinar 0 curso com a realidade vivida pelo dirigente, dar-lhe atribuições extras (delegações especiais) ou fazê-lo participar de grupos de decisão (para tratar de problemas que devam ser resolvidos por juntas de dirigentes) são medidas que reforçam o programa de desenvolvimento.

Nenhum curso é capaz de ensinar alguém a ser administrador. Mas, a aplicação dos ensinamentos adquiridos no desempenho do cargo reduz muito o tempo de aprendizagem. Admitido que o exercício bem orientado da função forma o administrador, o treinamento acelera seu desenvolvimento, reduzindo os riscos de uma aprendizagem defeituosa. Assim, a prática do trabalho, mormente o exercício da decisão, determinará o administrador. O que através de ensaio e êrro levaria anos o treinamento pode reduzir a alguns meses.

A aprendizagem no trabalho apresenta as seguintes vantagens: (a) coloca em prática conhecimentos teóricos, (b) faz com que os problemas surjam tais como são, dentro de seu ambiente próprio, em função de pessoas e coisas reais, e (c) permite a influência direta dos chefes na solução dêsses problemas. 
Sempre que alguém se defronta com um problema ou se vê na contigência de tomar decisões vive uma situação de autodesenvolvimento. É nessas circunstâncias que o homem assume um compromisso próprio da ação: o risco do êrro.

Errar quando se extrai do êrro experiência que reforce positivamente o certo é, ainda, uma das formas mais eficientes de autodesenvolvimento. Mede-se um administrador por suas decisões, não pelos seus erros. Errar é contingência normal de quem age. "Quem se omite não comete erros", dizem. Todavia, comete o pior dos erros: o de aceitar tôdas as desastrosas conseqüências de sua omissão.

Sob o aspecto pedagógico, o exercício do cargo representa o melhor método de formação de administradores porque faculta o treinamento no que é vital à função: a técnica da resolução de problemas, bem como a habilidade e presteza em tomar decisões certas, oportunas e rápidas. Nenhum outro método de treinamento substitui a realidade do trabalho. Sem orientação e acompanhamento, todavia, a fôrça educativa da vivência profissional é amortecida ou até extinta pelo espírito de rotina e pela incapacidade para estabelecer perspectivas e decidir oportuna e tècnicamente.

É necessário, portanto, que cada um sinta o trabalho como um permanente apêlo ao desenvolvimento pessoal e identifique em cada problema não só um desafio à sua capacidade, mas também uma oportunidade de treinamento e formação.

Assim, em grande parte, o desenvolvimento é assunto individual. É preciso que o executivo esteja motivado a aperfeiçoar-se, que seus anseios encontrem repercussão, que sinta as oportunidades, que as frustrações sejam reduzidas ao mínimo.

O desenvolvimento implica numa atitude positiva dos administradores, reconhecida pelos altos escalóes através de práticas administrativas que ensejem um clima de aperfeiçoamento onde todo o esfôrço de treinamento seja valorizado. 
O êxito de um programa de autodesenvolvimento depende de um sistema regular de acompanhamento pelos superiores hierárquicos.

Para que se propicie um programa de autodesenvolvimento é preciso executar a prática eficiente da delegação de autoridade, estimulando-se a execução das funções administrativas fundamentais (planejamento, organização, motivação e contrôle) em todos os escalões da emprêsa.

A centralização administrativa não produz administradores, mas sim especialistas. A descentralização através da prática da delegação constitui, por si só, um dos mais eficientes processos de formação administrativa.

A descentralização administrativa pelo uso da delegação de autoridade estende a presença do administrador. Mediante êsse expediente a autoridade se reflete pelos vários níveis; cada chefe passa a representar a extensão do seu superior e a agir como tal.

No delegar não se exclui a responsabilidade: amplia-se o seu exercício. Assim, para conhecer no trato diário de suas atividades os problemas administrativos em todos os seus aspectos, levantar alternativas de solução e fazer com que suas decisões sejam cumpridas o dirigente depende da cooperação do grupo. Destarte, a posição do dirigente, se de um lado é de independência (pelo seu poder de decisão), torna-se dependente quando se trata de transformar a decisão em ação.

A decisão envolve pessoas que devam ser ouvidas, leis que devam ser cumpridas, circunstâncias que devam ser consideradas e executores que, adequadamente motivados, apresentem condições técnicas e psicológicas que lhes possibilitem transformar em ação as resoluções. Logo, é curial ao administrador considerar que seu desenvolvimento depende, em grande parte, da capacidade de promover o desenvolvimento do seu pessoal. Se o administrador depende de outros para produzir, o desenvolvimento dêstes significa, sob muitos aspectos, o seu próprio desenvolvimento. 
A função instrutora do administrador representa uma de suas maiores responsabilidades.

$O$ chefe deve proporcionar oportunidades de desenvolvimento aos seus subordinados cuidando de avaliar se estão bem ajustados às funções, o que mais precisem saber $\mathbf{e}$ quais as deficiências que devam ser corrigidas.

Os resultados dessa avaliação poderão aconselhar, por exemplo, uma transferência que melhor ajuste o indivíduo às suas funções ou the possibilite novas experiências; um programa formal de treinamento através de cursos, seminários, estudos etc.; a outorga de uma missão especial para resolver problemas relativos a novos processos de trabalho ou a ampliação de políticas etc..

\section{A FORMAÇÃO DO SUBSTITUTO}

Finalmente, o administrador deve considerar como sua indeclinável responsabilidade formar seu substituto.

Um dirigente que se considere indispensável está física, técnica e socialmente condenado à morte! Quanto à morte física, que o digam os enfartes e úlceras provenientes das tensões a que se submete um dirigente autocrata, centralizador, "indispensável". A morte técnica é a que ocorre quando o pessoal deixa de constituir um grupo pensante $e$ criativo para transformar-se numa engrenagem de trabalho manobrada à fôrça. E êle morre socialmente quando o seu egocentrismo se reflete - no campo das relações humanas - pelos ciúmes, rivalidades, desavenças... numa palavra: pela decomposição da equipe.

Quase sempre, com a queda da produtividade grupal, a produção decai vertiginosamente ou se mantém em níveis medianos. Pode acontecer, ocasional e paradoxalmente, que a produção se mantenha alta. Às vêzes, as ditaduras conseguem, à base de pressão, resultados materiais compensadores. Mas, basta que o dispositivo de coação se afrouxe para que a produção entre em colapso. O dirigente "insubstituivel" é um perigo para a emprêsa e para si próprio. 
Quem não delega e com isso julga tornar-se insubstituível prova apenas que é impromovível.

Prática eficaz de treinamento pelo autodesenvolvimento é a de possibilitar oportunidades de convívio dos subalt. $\mathrm{rnnos}$ com seus superiores. Êsses contatos, pelas observações que facilitam, alargam o conhecimento, adestram atitudes, abrem os horizontes. ( $\mathrm{O}$ cargo ideal de treinamento para chefia é o de assistente da chefia.)

Passo importante a ser considerado na promoção à chefia é a preparação do candidato para que se compenetre das reais responsabilidades do cargo. Para fazer com que um caixa, balconista ou correntista se torne um chefe e para que êste venha a ser um dirigente mais qualificado não basta promovê-lo, pois não será suficiente delegar-lhe autoridade, se êle continuar a pensar e agir como correntista, caixa ou balconista. Fazer com que pensem como dirigentes para que possam ter atitudes diretrizes - eis o maior desafio aos que pretendem formar administradores!

Para que alguém esteja habilitado a tomar atitudes de chefia é preciso que se submeta a um programa de treinamento em que a aprendizagem no exercício da função, que the possibilite enfrentar problemas administrativos reais, seja a primeira providência. Para tanto é de todo conveniente que o seu superior hierárquico lhe proporcione essa oportunidade, principalmente através da delegação de podêres.

\section{CONCLUSĀO}

Podemos concluir que um plano de desenvolvimento de administradores visa, sobretudo, a prepará-los para que possam assumir maiores responsabilidades, sempre de conformidalde com a sua experiência adquirida, com os conhecimentos técnicos que lhes facilitem o equacionamento dos problemas, e com a sua capacidade para resolver casos e problemas pelo exercício da decisão. 
Acreditamos, dêsse modo, que qualquer plano de desenvolvimento de administradores deva considerar como funções fundamentais de um dirigente: (a) organizar o trabalho, (b) dirigir (com liderança) o trabalhador e (c) "viver" a filosofia e a política administrativas da emprêsa, dando-lhe expressão através de práticas adequadas. 